\title{
Optical Properties of Normal and Diseased Breast Tissues: Prognosis for OPTICAL MAMMOgRAPHY
}

\author{
Tamara L. Troy, ${ }^{\dagger}$ David L. Page, ${ }^{\dagger}$ and Eva M. Sevick-Muraca ${ }^{\dagger}$ \\ ${ }^{\dagger}$ Purdue University, School of Chemical Engineering, West Lafayette, Indiana 47907; ${ }^{\dagger}$ anderbilt \\ University, Vanderbilt School of Medicine, Nashville, Tennessee 37235 \\ (Paper JBO-073 received Feb. 7, 1996; revised manuscript received Apr. 11, 1996; accepted for publication Apr. 15, 1996)
}

\begin{abstract}
The use of near-infrared (NIR) measurements of photon migration has been recently demonstrated for the detection of breast cancer in Europe. Yet the clinical success of this potential screening tool depends upon consistent detection of the disease at earlier stages than is currently possible with conventional x-ray mammography. In this paper, we present the optical property measurements of 115 histologically classified breast tissue specimens in order to determine whether consistent and significant optical contrast exists for detection of the disease. Our in vitro optical properties measured with a double integrating sphere technique show consistent changes (yet statistically insignificant) in effective scattering coefficients, $\mu_{s}{ }^{\prime}$, with tissue classification of infiltrating carcinoma $(n=48)$, ductal carcinoma in situ $(n=5)$, mucinous carcinoma $(n=3)$, normal fatty $(n=23)$, and normal fibrous tissues $(n=35)$. However, there is little change in the in vitro tissue absorption coefficient, $\mu_{a}$, measured at 749, 789, and $836 \mathrm{~nm}$. For normal and diseased tissue specimens extracted from the same patient, we found differences in optical properties, indicating optical contrast. Using a finite-element prediction of light propagation, we evaluated this optical contrast for photon migration detection of ductal carcinoma in situ tissues using these optical properties measured in vitro. (c) 1996 Society of Photo-Optical Instrumentation Engineers.
\end{abstract}

Keywords optical mamography; photon migration imaging; tissue scattering; tissue absorption; breast cancer screening.

\section{INTRODUCTION}

One out of every eight women in the U.S. will encounter breast cancer in her lifetime. ${ }^{1}$ While x-ray mammography is generally an effective screening tool against the disease, studies have shown that mortality rates in women less than 40-50 years of age are not positively influenced by this screening method. In this age group, x-ray mammography has an unacceptable $50 \%$ false negative rate. ${ }^{2}$ Consequently, numerous research groups have embarked upon nonionizing, near-infrared (NIR) approaches for detecting and imaging diseased breast tissues. The proposed techniques range from CW (continuous wave) or time-independent measurements of scattered light ${ }^{3}$ to snake-light measurements of unscattered light $t^{4,5}$ and photon migration or time-dependent measurements of multiply scattered light. ${ }^{6-8}$ In each of these techniques, light that has been transmitted across several centimeters of tissue is detected.

Perhaps the most promising technique lies with photon migration measurements. Photon migration imaging consists of measuring the time-dependent

Address all correspondence to Eva M. Sevick-Muraca. E-mail: sevick@ecn.purdue.edu characteristics of light propagation and then reconstructing an image of normal and diseased tissues based upon their optical properties. Similar to ultrasound and impedance tomography, the reconstructions are based upon an iterative approach in order to converge upon a "map" of tissue optical properties which gives the minimum error between the measured photon migration characteristics, ${ }^{6,9,10}$ and that predicted by the optical diffusion equation. ${ }^{11}$ The endogenous optical contrast for detection of diseased tissues can be provided by (1) the local tissue absorption coefficient, $\mu_{a}$, which arises primarily due to hemoglobin and increased vascular volumes associated with tumor angiogenesis, and (2) the isotropic tissue scattering coefficient, $\mu_{s}{ }^{\prime}$, which in the NIR regime arises primarily due to mitochondria ${ }^{12,13}$ and predominates over absorption. Numerous investigators report reconstructed images based upon differences in absorption and scattering. O'Leary and co-workers ${ }^{14}$ report success in reconstructing images of a 1.0 to $2.0-\mathrm{cm}$ diameter heterogeneity embedded in a $6 \times 6 \mathrm{~cm}$ tissuemimicking scattering medium from experimental photon migration measurements made in the frequency domain (Table 1 ). Pogue et al. ${ }^{9}$ have dem-

1083-3668/96/\$6.00 (C) 1996 SPIE 
Table 1 Summary of simulated and experimental optical properties used for image reconstruction found in literature.

\begin{tabular}{|c|c|c|c|c|c|c|}
\hline \multirow[b]{2}{*}{ Reference } & \multicolumn{3}{|c|}{ Surroundings } & \multicolumn{3}{|c|}{ Heterogeneity } \\
\hline & Size & $\mu_{a}\left(\mathrm{~cm}^{-1}\right)$ & $\mu_{s}^{\prime}\left(\mathrm{cm}^{-1}\right)$ & (diameter) & $\mu_{a}\left(\mathrm{~cm}^{-1}\right)$ & $\mu_{s}^{\prime}\left(\mathrm{cm}^{-1}\right)$ \\
\hline \multirow[t]{4}{*}{$\mathrm{O}^{\prime}$ Leary $^{14}$} & $\begin{array}{l}6 \times 6 \mathrm{~cm} \\
\text { square }\end{array}$ & 0.023 & 6.0 & 1.2 & $\begin{array}{l}\text { perfect } \\
\text { absorber }\end{array}$ & - \\
\hline & $\begin{array}{l}6 \times 6 \mathrm{~cm} \\
\text { square }\end{array}$ & 0.023 & 6.0 & 1.2 & 0.023 & 15 \\
\hline & $\begin{array}{l}6 \times 6 \mathrm{~cm} \\
\text { square }\end{array}$ & 0.1 & 6.0 & $\begin{array}{c}1.0 \\
\text { (2 objects) }\end{array}$ & 0.4 & 6.0 \\
\hline & $\begin{array}{l}6 \times 6 \mathrm{~cm} \\
\text { square }\end{array}$ & 1.0 & 6.0 & $\begin{array}{c}1.0 \\
\text { (2 objects) }\end{array}$ & 4.0 & 6.0 \\
\hline \multirow[t]{3}{*}{ Pogue $^{9}$} & $\begin{array}{l}8.6 \mathrm{~cm} \\
\text { diameter } \\
\text { cylinder }\end{array}$ & 0.047 & 4.7 & $\begin{array}{c}2.5 \\
\text { cylinder }\end{array}$ & 0.075 & 4.7 \\
\hline & $\begin{array}{l}8.6 \mathrm{~cm} \\
\text { diameter }\end{array}$ & 0.047 & 4.7 & $\begin{array}{c}2.5 \\
\text { cylinder }\end{array}$ & 0.047 & 9.4 \\
\hline & & & Contrast & & & Contrast \\
\hline \multirow[t]{2}{*}{ Barbour $^{10}$} & \multicolumn{2}{|c|}{$41 \times 41 \times 10 \mathrm{mfp}$} & $\tau=0.01 *$ & \multicolumn{2}{|c|}{$1 \mathrm{mfp}^{3}$} & $\tau=0.05^{*}$ \\
\hline & \multicolumn{2}{|c|}{$\begin{array}{c}\sim 4.1 \times 4.1 \times 0.1 \mathrm{~cm} \\
\text { for tissue }\end{array}$} & & \multicolumn{2}{|c|}{$\begin{array}{l}\sim 1 \mathrm{~mm}^{3} \\
\text { for tissue }\end{array}$} & $\begin{array}{l}\mu_{a}=5 \mu_{a}^{\text {surr }} \\
\mu_{s}^{\prime}=\mu_{s}^{\prime} \text { surr }\end{array}$ \\
\hline
\end{tabular}

$*_{\tau=}\left(\frac{\mu_{a}}{\mu_{s}+\mu_{a}}\right)$.

onstrated reconstructions from experimental frequency domain measurements for a $8.6 \mathrm{~cm}$ diameter homogeneous medium with a $2.5 \mathrm{~cm}$ diameter heterogeneity (Table 1 ). Their results show that image reconstructions can be severely degraded by boundaries that are unaccounted for. Jiang and Paulsen show reconstruction of $4 \mathrm{~mm}$ diameter heterogeneities in an 8.6- $\mathrm{cm}$ diameter tissue phantom..$^{15}$ Barbour and co-workers ${ }^{10}$ show simulations that point to the detection of heterogeneities as small as $1 \mathrm{mfp}\left(\sim 1 \mathrm{~mm}^{3}\right.$ for tissues) (Table 1). Instead of using reconstructed images, Sevick et al. ${ }^{16}$ demonstrated that multipixel measurements of frequency-domain photon migration can be used to construct a phase-shift and amplitude modulation map in order to detect optical heterogeneities directly. Recently, Franceschini and co-workers ${ }^{17}$ demonstrated that in vivo single-pixel measurements of phase-shift and amplitude modulation may also be used to directly construct an optical mammogram. Their results show that photon migration can effectively detect carcinomas that have been previously identified by x-ray mammography. Thus, the feasibility of photon migration imaging for detecting breast cancer has already been demonstrated. The capabilities improving detectability of the disease beyond that currently possible with conventional $\mathrm{x}$-ray mammography may depend upon (1) the successful implementation of developing image reconstructions and (2) the degree of contrast, $\Delta \mu_{a}$ and $\Delta \mu_{s}{ }^{\prime}$ or the differences in absorption and scattering properties that must exist between normal and diseased tissue for effective detection.

In this article, we present in vitro measurements of optical properties of 115 normal and diseased breast tissues characterized by histology in order to assess the optical contrast, or $\Delta \mu_{a}$ and $\Delta \mu_{s}{ }^{\prime}$. In addition, we provide in vitro measurements of normal and diseased tissues obtained from five patients in order to assess whether the presence of disease will affect measurement of photon migration and provide detection, whether inversion algorithms or direct imaging techniques are employed. Finally, using the optical properties measured in these studies, we demonstrate the impact of endogenous contrast using finite-element predictions of changes in photon migration due to a tumor embedded in an otherwise homogeneous tissue.

\section{EXPERIMENTAL MEASUREMENT OF TISSUE OPTICAL PROPERTIES}

Tissue optical property measurements are fraught with difficulties owing to (1) the necessity of ex- 
tracting tissues, thereby enabling the drainage of hemoglobin, (2) the maintenance of tissue viability under measurement conditions, and (3) the accuracy of measurement techniques. Nonetheless, the best possible method of measuring normal and diseased optical properties is a noninvasive measurement. For diseased tissues, this would require an accurate "map" or image of in vivo tissue optical properties. As described earlier, this has yet to be demonstrated using reconstructed images from $\mathrm{CW}$ or photon migration measurements. Since we attempt to assess or estimate the contrast required for such measurements and reconstructions, we conduct our optical property measurements of whole normal and diseased breast tissues using in vitro techniques, keeping in mind the issues of blood drainage, maintenance of tissue viability, and accuracy of measuring technique.

\subsection{TISSUE SPECIMENS}

Measurements were conducted on 115 tissue samples collected from 88 patients. The tissue samples were obtained from the Pathology Department at the Vanderbilt University Medical School with prior patient consent. Of the specimens collected, two were freshly obtained from the surgical suite, placed upon ice, and transported to the Engineering School for optical property measurements. Since freshly excised tissue samples were generally not available and since we found that optical properties were not influenced by freezing and subsequent thawing (see Sec. 2.4), the remainder of our samples were frozen specimens. All specimens were procured from punch biopsy from tissues obtained from lumpectomies, mastectomies, or breast reduction surgeries. The human subject protocol guidelines of Vanderbilt and Purdue universities were strictly followed.

For optical property measurements, fresh or thawed tissue samples were carefully cut into approximately 1-mm-thick slices using a scalpel and taking care to avoid tissue compression. Previously frozen samples were thawed at room temperature. The tissue slices were wetted with saline and placed between two microscope slides, which were then sealed with silicon gel to prevent dehydration. The addition of saline also prevented tissue-glass mismatch of refractive index. ${ }^{18}$ Caliper measurements were then made to provide an accurate measurement of the tissue sample thickness. For heterogeneous samples, more than one tissue section was optically examined.

Following optical property measurements, tissue samples were placed in formalin for storage and transport back to the Vanderbilt pathology laboratories. There the samples were embedded in paraffin, sectioned, and stained with hematoxylin and eosin, and mounted on microscope slides for histopathological examination. The pathology of each sample was classified into one of five categories: infiltrating carcinoma, ductal carcinoma in situ, mucinous carcinoma, normal fatty, or normal fibrous tissues. In the case of disease, observations of high-, intermediate-, and low-grade carcinomas were reported along with the percentage of diseased tissue content in the specimen as determined by the pathologist.

\subsection{DOUBLE INTEGRATING SPHERE MEASUREMENTS OF TISSUE OPTICAL PROPERTIES}

Figure 1 illustrates the double integrating sphere apparatus used to measure the diffuse reflectance and transmittance in order to determine tissue optical properties of each specimen. For a complete description of integrating sphere technology, the reader is directed to other excellent treatises on the subject. ${ }^{19}$ The tissue specimen was placed between two $15.2 \mathrm{~cm}$ diameter integrating spheres (70451, Oriel, Stratford, Connecticut) with internal baffles positioned to prevent measurement of directly reflected or transmitted light. The tissue sample was maintained at $37^{\circ}$ Celsius by forced convection using a temperature controller and temperature probe (Fisher Scientific, Atlanta, Georgia).

Diffuse transmitted and reflected light was measured with sample illumination at 749,789 , and 830 $\mathrm{nm}$ provided by 5,30 , and $40 \mathrm{~mW}$ collimated laser diodes (06DLS103, 06DLS403, 06DLS503, Melles Griot, Carlsbad, California). The beam was elliptical with $1.3 \times 4.0-\mathrm{mm}$ axes, and the sample port was reduced to $12 \mathrm{~mm}$ because of the limited size of tissue specimens available. Photodetector (71822, Oriel, Stratford, Connecticut) signals were amplified (70710, Oriel, Stratford, Connecticut) to record diffuse reflectance and transmittance from the first and second spheres respectively. Signals were acquired by a standard computer A/D acquisition, and detector calibrations were performed with reflectance standards (70497, Oriel, Stratford, Connecticut). ${ }^{18}$ From diffuse reflectance and transmittance measurements, values of scattering and absorption were obtained using the inverse adding doubling program provided by Professor Scott Prahl at the Laser Research Center at St. Vincent Hospital, Portland, Oregon. These computations assumed an anisotropy parameter, $g$, equal to $0.9^{20}$ On each specimen, the incident beam was focused onto three different locations. The results of tissue absorption and scattering are reported as the mean \pm the standard deviation of the values obtained from the three measurements made on the same sample.

\subsection{VALIDATION OF OPTICAL PROPERTY MEASUREMENTS}

In order to validate the double integrating sphere and inverse adding doubling procedures used, we determined the scattering and absorption coefficients of monodisperse polystyrene microsphere 


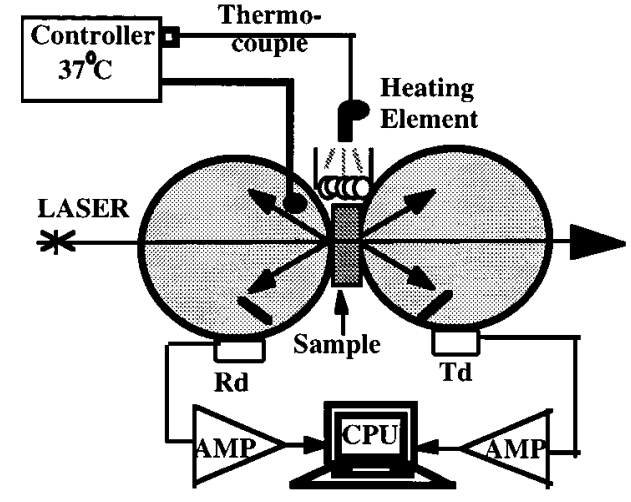

Fig. 1 Schematic of the double integrating sphere apparatus.

suspensions with and without the addition of a broadband absorbing dye. A comparison of results with theoretical predictions provided confidence of our measurement of tissue optical properties.

\subsubsection{Scattering Coefficients of Monodisperse Polystyrene}

In a $100 \times 100 \times 1$-mm glass sample chamber constructed from microscope slide glass (Erie Scientific, Portsmouth, New Hampshire), monodisperse polystyrene suspensions (Polysciences, Inc., Warrington, Pennsylvania) of radii 0.101, 0.185, 0.390, $0.475,0.719$, and $1.043 \mu \mathrm{m}$ and concentrations varying between 0.625 and $2.5 \%$ by volume were examined at 633 (05-LLR-811, Melles Griot, Irvine, CA), 749 , and $836 \mathrm{~nm}$ in the apparatus shown in Figure 1 . Values for the anisotropy parameter, $g$, for each suspension were computed from Mie scattering theory. ${ }^{21}$ Together with measurement of diffuse reflectance and transmittance, values of scattering and absorption were obtained from the inverse adding doubling algorithm. A value of 1.60 was assumed for the refractive index of polystyrene. ${ }^{22}$ The values of scattering obtained from experimental measurements and the inverse adding doubling algorithm were then assumed to be linearly related to the volume fraction, $\phi$, via the expression [where $\left.\mu^{\prime}{ }_{s}=\mu_{s}(1-g)\right]$ :

$$
\mu_{s}=\frac{Q_{\text {scat }} \pi r^{2}}{\frac{4}{3} \pi r^{3}} \phi .
$$

From measurements of scattering $\mu_{s}$ versus volume fraction $\phi$ for each microsphere radii $r$ we computed the Mie scattering efficiency, $Q_{\text {scat }}$. Figure 2 shows the typical agreement between $Q_{\text {scat }} / r$ predicted by Mie scattering theory and that obtained from integrating sphere measurements at 633, 749, and $836 \mathrm{~nm}$. These results validate the measurement of scattering coefficient from the integrating sphere technique. (a)

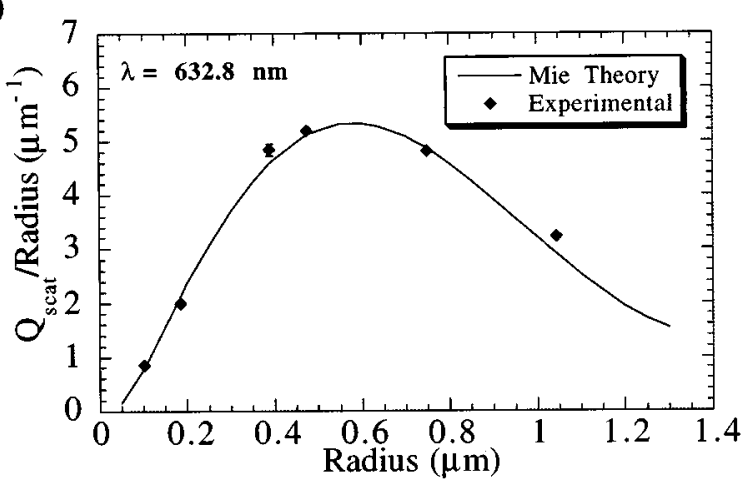

(b)

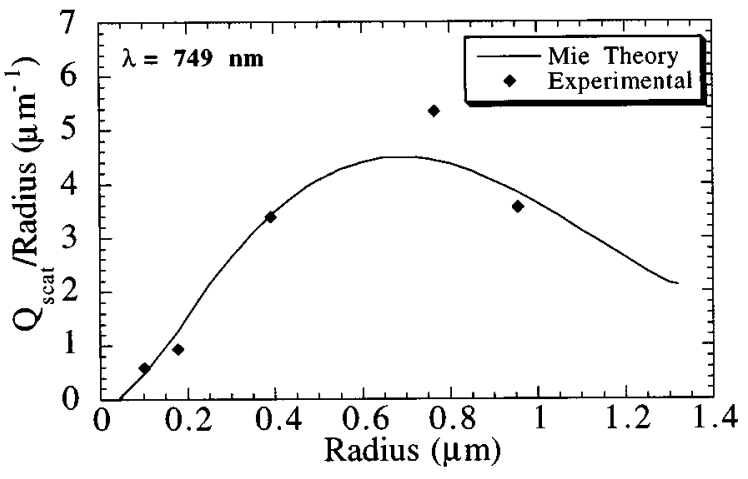

(c)

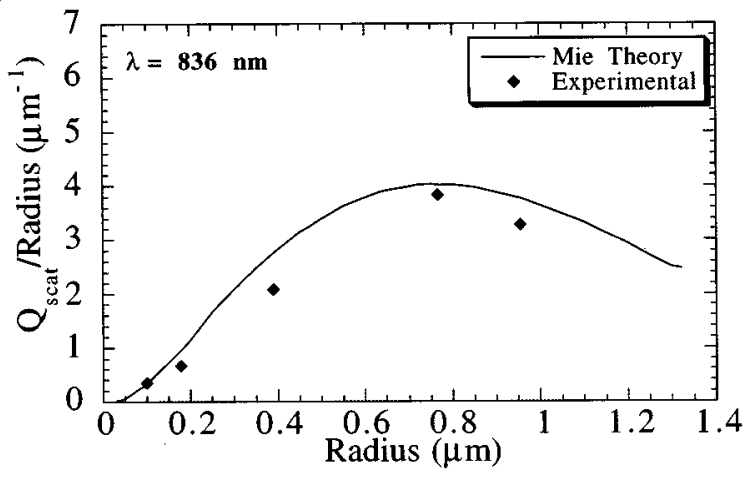

Fig. 2 The efficiency of scatter $\left(Q_{\text {scat }}\right)$ divided by the particle radius versus the particle radius at wavelengths of (a) 632.8 , (b) 749 , and (c) $836 \mathrm{~nm}$ where the solid line represents that predicted by Mie scattering theory and the symbols are the measured values from the integrating sphere technique.

\subsubsection{Absorption Coefficient Measurements of Monodisperse Polystyrene Microspheres}

Since light losses may be significant when the ratio of beam diameter to sample port diameter is less than $0.04{ }^{18}$ we expected the measured absorption properties to be overestimated by double integrating sphere measurements. In order to account for light losses, absorption and scattering coefficients of a monodisperse polystyrene suspension with added absorber were measured and compared against theoretical predictions of scattering coefficients that were computed from Mie theory and ab- 


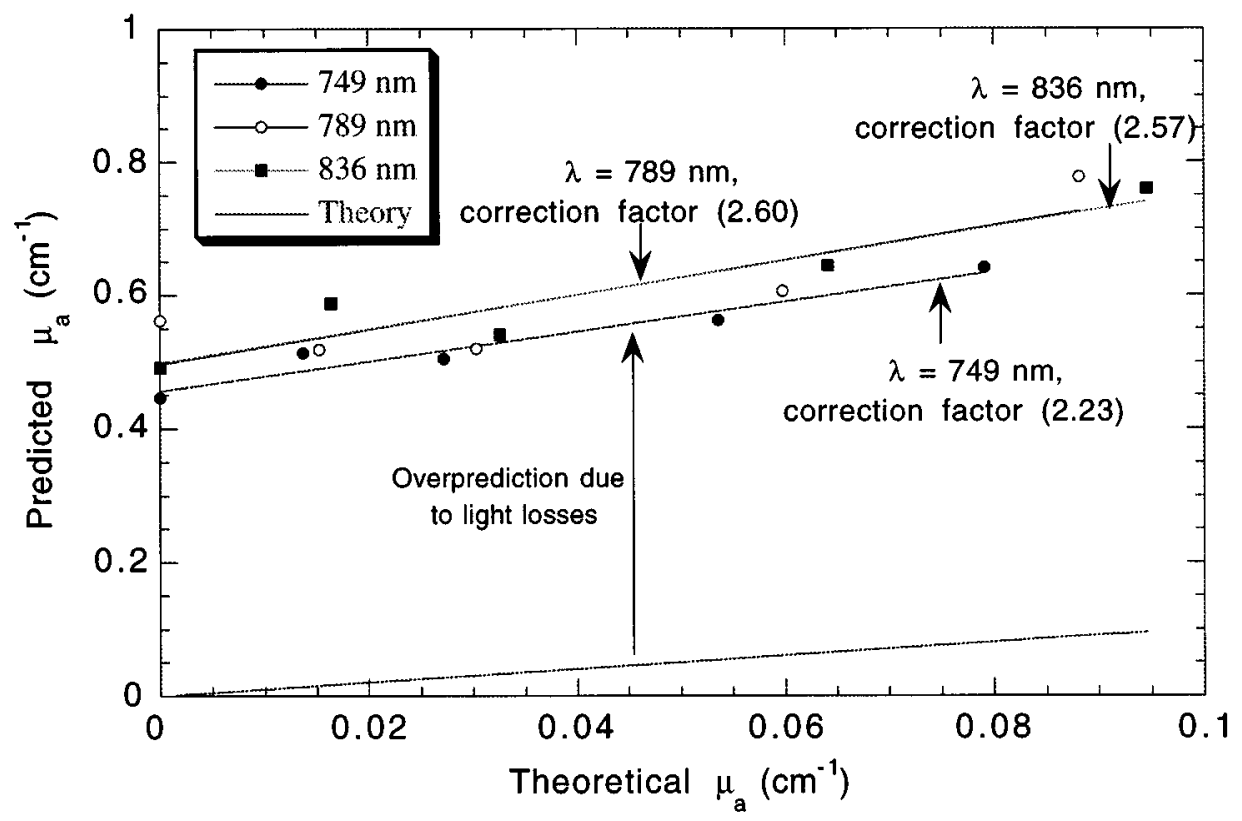

Fig. 3 The predicted absorption coefficient $\mu_{a}$ measured by the integrating spheres and the inverse adding doubling algorithm versus the theoretical $\mu_{a}$. The slopes are $2.23,2.60$, and 2.57 , and intercepts are $0.457,0.497$, and 0.498 for $\lambda=749,789$, and $836 \mathrm{~nm}$ respectively.

sorption coefficients that were obtained spectroscopically from nonscattering solutions of a broadband absorber (S109554, Imperial Chemical Industries, Manchester, England). A microsphere $0.53 \mu \mathrm{m}$ in radius was chosen since its anisotropy parameter most closely corresponded to tissue at the wavelengths studied. Small amounts of dye were introduced so that the final absorption coefficient $\mu_{a}$ was between 0 and $0.1 \mathrm{~cm}^{-1}$ in a suspension of microspheres with an isotropic scattering coefficient $\mu_{s}^{\prime}$ of around $12 \mathrm{~cm}^{-1}$.

From measurements of diffuse reflectance and transmittance, accurate measurements of scattering coefficients were found as the dye concentration increased (data not shown for brevity). However, as shown in Figure 3, light losses due to the small port size caused a consistent overestimation of the absorption coefficient obtained from the double integrating sphere measurement and the inverseadding doubling algorithm. Since the relationship between the true and the measured absorption coefficient remained consistent within the range of wavelengths studied and within the range of microsphere sizes and concentrations employed, we used the slopes and intercepts of Figure 3 to correct for tissue absorbance measurements. Previous investigators also have employed correction factors (S. L. Jacques, personal communication, Jan. 11, 1995), Monte Carlo corrections, ${ }^{23}$ and larger port sizes, ${ }^{24}$ to correct for the artifact of light losses. Since tissue extraction causes drainage of blood and the absorption coefficient may be dramatically affected, we used the correction factor as an approach to estimate tissue absorbance. Due to the restrictions of obtaining larger tissue specimens, we were unable to employ a smaller beam-to-port size ratio to minimize light losses.

\subsection{VALIDATION OF TISSUE SPECIMEN MEASUREMENT}

Since it was anticipated that frozen tissue specimens would have different optical properties than freshly harvested samples, we evaluated the impact of freezing and subsequent thawing at room temperature on the optical properties obtained from the double integrating sphere measurements. Two freshly harvested normal tissue samples were repeatedly frozen in liquid nitrogen and thawed for optical property measurement at $633 \mathrm{~nm}$. On a 99\% confidence level, there was no significant difference in the optical properties between previously frozen and thawed tissue specimens. Even though histological evidence shows the morphological changes with freeze/thaw, the mitochondrial compartment, which may be the major cellular constituent responsible for tissue scatter, ${ }^{12,13}$ remains intact and presumably provides constant tissue scattering properties (B. Chance, personal communication).

On the other hand, when diffuse reflectance and transmittance measurements are conducted at different temperatures, large differences exist in tissue optical properties. For example, Figure 4 illustrates the temperature dependence of the optical property measurements of the canine prostate. With increasing temperatures, the scattering coefficient increases dramatically, owing to the degradation of cellular components. 


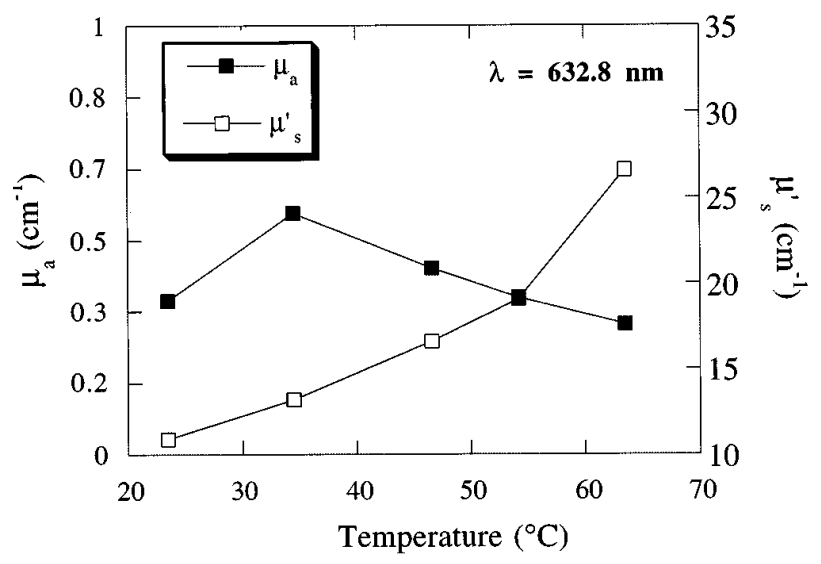

Fig. 4 Absorption coefficient $\mu_{a}$ (open square) and isotropic scattering coefficient $\mu_{s}^{\prime}$ (closed square) of canine prostate tissue as a function of temperature measured at a wavelength of $632.8 \mathrm{~nm}$.

\section{EXPERIMENTAL MEASUREMENTS PREDICTING $\mu_{a}$ AND $\mu_{s^{\prime}}$ OF POOLED NORMAL AND DISEASED BREAST TISSUES}

Table 2 is a comprehensive listing of the scattering and absorption coefficients at each wavelength, as well as the histological classification and comments for each tissue specimen in the current study. Each tissue was classified into one of five groups: infiltrating carcinoma, ductal carcinoma in situ, mucinous carcinoma, normal fatty, and normal fibrous tissues. As shown in Table 2, correction of absorbances resulted in some small negative values. In these cases the standard deviation of the measurement was larger than the mean, indicating inaccurate measurement and prediction of $\mu_{a}$. Since the error in $\mu_{a}$ due to blood loss is unavoidable in this study, we did not attempt to make further corrections as others have done using Monte Carlo techniques. ${ }^{23,25}$ Figures 5(a) through 5(c) illustrate the compilation of scattering and absorption coefficients of normal and diseased tissues which include the groupings of fibrous and fatty (open circles) tissues and of infiltrating carcinoma, ductal carcinoma in situ, and mucinous disease classifications (closed circles). Since no distinct population of normal versus diseased tissues is apparent in our scatter plots and since there is no statistical difference in optical properties between these two groupings, we evaluated the optical properties of individual classifications (Table 3). In addition, we found no correlation of normal and/or diseased tissues with age and optical properties.

Table 3 lists the optical properties for tissues classified into each of the five categories. While there is no statistical difference between the absorption and scattering properties of normal fatty and normal fibrous tissues, our results show that the scattering coefficient of fatty tissues is lower than that of fibrous tissues. Fatty tissues are identified by the presence of a mature adipose tissue component that is histologically transparent, while fibrous normal tissues exhibit glandular components that have variations in the density of epithelial glands and ducts. Our optical property measurements reflect these morphological differences, which are illustrated in Figure 6(a). Peters et al. ${ }^{25}$ have also measured the optical properties of several homogenized breast tissues. They report that the scattering coefficient of homogenized adipose tissues is smaller than that of homogenized glandular and fibrocystic tissues, which is consistent with our results. However, no direct comparisons can be made since their tissue measurements were conducted at room temperature and their specimens were homogenized for tissue uniformity.

Mucinous carcinoma is a comparatively rare disease in which cancer cells secrete extracellular mucin, thereby providing a transparent tissue component in which cancer cells float or reside. An example of a mucinous carcinoma is illustrated in Figure 6(b). Interestingly, Table 3 shows that the scattering coefficient of mucinous carcinoma samples is statistically smaller than infiltrating carcinoma at an $80 \%$ confidence level at 749 and 836 $\mathrm{nm}$ and at a $90 \%$ confidence level at $789 \mathrm{~nm}$. Differences in the scattering coefficient between mucinous carcinoma and ductal carcinoma in situ occur at a 90\% confidence level for 749 and $789 \mathrm{~nm}$ and at $80 \%$ for $836 \mathrm{~nm}$. The scattering coefficient of mucinous carcinoma was found to be statistically lower than fibrous tissues at a 95\% confidence level for all wavelengths studied. No difference in the scattering coefficient between mucinous carcinoma and fatty tissues was found at $749 \mathrm{~nm}$, but at an $80 \%$ confidence level, mucinous carcinoma was found to be statistically lower at 789 and $836 \mathrm{~nm}$.

Infiltrating carcinoma is characterized by increased cellularity and enlarged nuclei, depending upon its grade. As with the ductal carcinoma in situ, the degree of increased cellularity and enlarged nuclei characterize the grade: high-grade carcinomas exhibit high cellularity and nuclei content consistent with the aggressiveness of the disease while low-grade carcinomas exhibit inverse features. ${ }^{26}$ While ductal carcinoma in situ resembles infiltrating carcinoma, it differs in that it is confined to the ducts. Within the ductal carcinoma in situ classifications, there are also variations in histological patterns that are indicative of prognosis. ${ }^{27}$ Figures 6(c) and 6(d) are micrographs illustrative of the these two diseased states. Our results show that there is no statistical difference at the $99 \%$ confidence levels between these two classifications. In addition, there is no significant statistical difference between the scattering coefficients of infiltrating carcinoma and normal fibrous tissues, and between the scattering coefficients of infiltrating carcinoma and normal fatty tissues. There is no statistical difference between the scattering coefficients of ductal carcinoma in situ and normal fibrous tissues, and 
Table 2 Optical properties and classificationof human breast tissue samples at wavelengths of 749, 789, and $836 \mathrm{~nm}$.

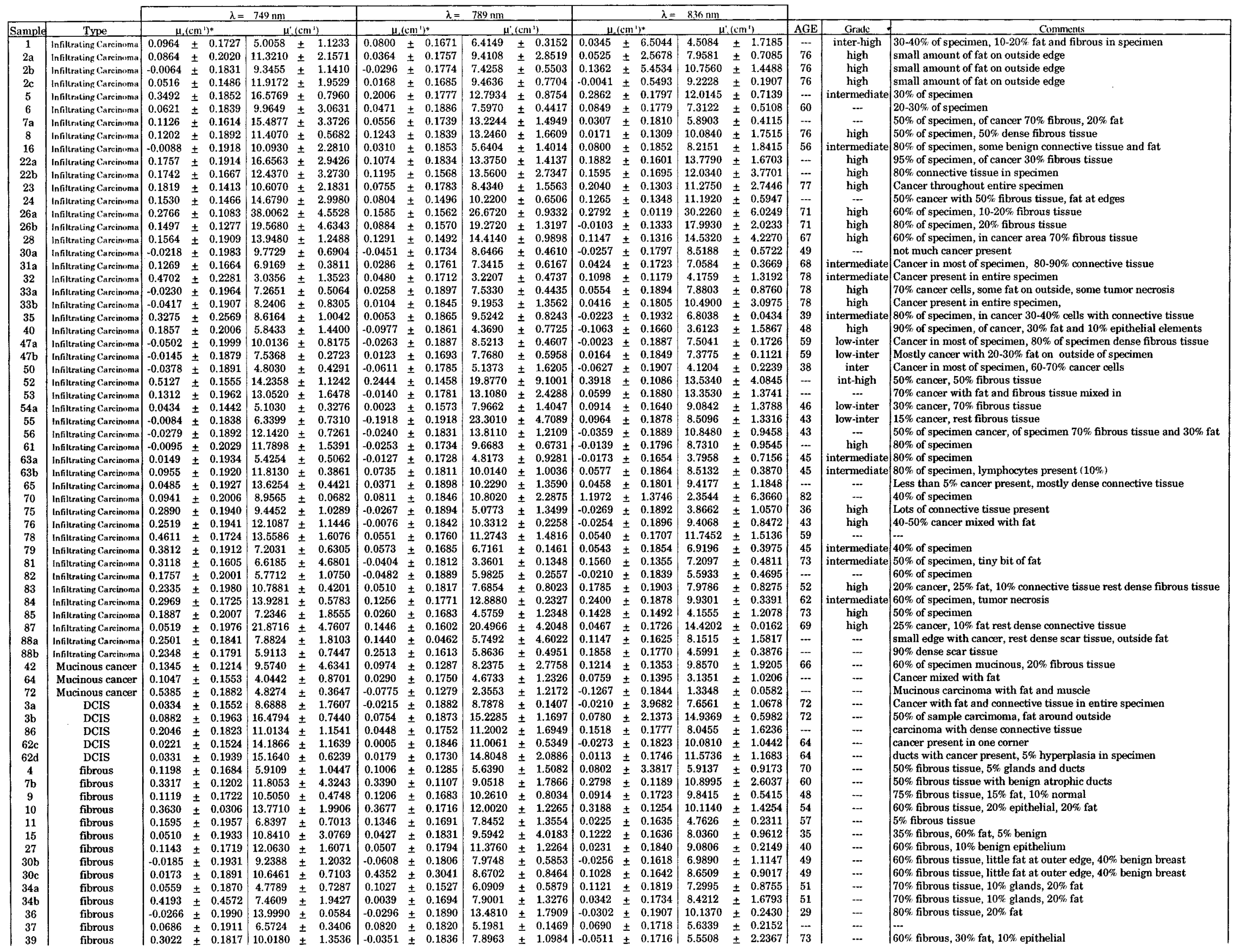


Table 2 (Continued)

\begin{tabular}{|c|c|c|c|c|c|c|c|c|c|c|c|c|c|c|c|c|c|}
\hline & & & & & & & & & & & \multirow{2}{*}{\multicolumn{4}{|c|}{$\lambda=8.3 \mathrm{~nm}$}} & \multirow{4}{*}{\begin{tabular}{|c|} 
AGE \\
69
\end{tabular}} & \multirow[b]{3}{*}{ Grade } & \multirow[b]{3}{*}{ Comments } \\
\hline \multirow{3}{*}{ Sample } & \multirow[b]{2}{*}{ Type } & \multicolumn{4}{|c|}{$\lambda=749 \mathrm{~nm}$} & \multicolumn{5}{|c|}{$\lambda=789 \mathrm{~nm}$} & & & & & & & \\
\hline & & \multicolumn{2}{|c|}{$\mu,\left(\mathrm{cm}^{\prime}\right)^{*}$} & \multicolumn{2}{|c|}{$\mu_{(}^{\prime}\left(\mathrm{cm}^{\prime}\right)$} & \multicolumn{2}{|c|}{$\frac{\left.\mu_{1}\left(\mathrm{~cm}^{\prime}\right)^{*}\right)}{0}$} & \multicolumn{3}{|c|}{$\mu_{i}\left(\mathrm{~cm}^{\prime}\right)$} & \multicolumn{2}{|c|}{$\left.\mu_{0}(\mathrm{~cm})^{\prime}\right)^{*}$} & \multicolumn{2}{|c|}{$\mu^{\prime}\left(\mathrm{cm}^{\prime}\right)$} & & & \\
\hline & fibrous & 0.2941 & \pm 0.1979 & $6.9392 \pm$ & \pm 0.2541 & $-0.0919 \pm$ & \pm 0.1692 & 4.3152 & & 8880 & $-0.0618=$ & \pm .0 .1758 & $4.7319 \pm$ & \pm 0.7217 & & $\cdots$ & $20 \%$ fibrous tissue, some fat \\
\hline & fibrous & 0.0424 & \pm 0.1924 & $12.1190 \pm$ & 0.4397 & $-0.0135 \pm$ & \pm 0.1855 & 9.9358 & & 1350 & $0.0168=$ & \pm 0.1910 & $10.8374 \pm$ & \pm 0.6894 & & $\ldots$ & $50 \%$ fibrous tissue and fat, $10-20 \%$ ducts in fibrous tissue \\
\hline $44 a$ & fibrous & 0.0050 & $\pm \quad 0.1831$ & $13.3042 \pm$ & 1.6504 & $-0.0013 \pm$ & \pm 0.1747 & 11.5217 & & 4596 & $0.0042=$ & \pm 0.1671 & $11.0265 \pm$ & \pm 1.4716 & 59 & ... & fibrous tissue with fat \\
\hline $44 \mathrm{~b}$ & fibrous & 0.0884 & 0.1921 & $13.1426 \pm$ & 0.6117 & $0.0594 \pm$ & \pm 0.1764 & 12.7912 & \pm 1 & .8448 & $0.0772=$ & 0.1757 & $12.7695 \pm$ & \pm 1.5954 & 59 & ... & fibrous tissue with fat \\
\hline 45a & fibrous & 0.0032 & 0.1982 & 13.1202 & 0.5491 & -0.0048 & 0.1841 & 12.2936 & \pm 0 . & .5634 & $0.0177=$ & 0.1768 & 10.6467 & 1.5486 & 50 & ... & $80 \%$ fbrous, $10 \%$ fat, $10 \%$ glands \\
\hline $45 \mathrm{~b}$ & fibrous & -0.0211 & 0.1980 & 10.5704 & 1.3677 & -0.0362 & 0.1852 & 10.3285 & 2. & 0598 & 0.0099 & 0.1853 & 8.7234 & 1.4264 & 50 & ... & $80 \%$ fibrous, $10 \%$ fat, $10 \%$ glands \\
\hline 46a & fibrous & 0.0139 & 0.1975 & 10.9489 & 3.6771 & 0.0045 & 0.1772 & 9.3028 & 2. & 6897 & 0.0482 & 0.1674 & $11.1347 \pm$ & 1.7276 & 44 & ... & $50 \%$ fibrous tissue, $50 \%$ fat, some hyperplasia \\
\hline $46 \mathrm{~b}$ & fibrous & 0.0152 & 0.1892 & 9.5271 & 2.1868 & $0.0025 \pm$ & \pm 0.1848 & 8.9343 & 1. & 3873 & 0.0416 & 0.1713 & $9.8990 \pm$ & \pm 0.5842 & 44 & ... & $50 \%$ fbrous tissue, $50 \%$ fat \\
\hline $47 \mathrm{c}$ & fibrous & 0.1683 & 0.1924 & 4.8698 & 0.5953 & $0.1210 \pm$ & $\begin{array}{l} \pm 0.1710 \\
\pm \quad 0\end{array}$ & 5.2128 & 0. & .5359 & 0.1530 & 0.1717 & 5.9967 & \pm 1.4157 & 59 & ... & $20 \%$ fbrous \\
\hline 47d & fibrous & 0.0532 & \pm 0.2014 & 5.9405 & 1.1875 & $0.0570 \pm$ & 0.1885 & 5.8476 & 1. & .1245 & 0.0683 & 0.1871 & 5.9520 & \pm 2.2828 & 59 & $\ldots$ & $50 \%$ fibrous, $50 \%$ fat \\
\hline 48 & fibrous & 0.0286 & \pm 0.2028 & $11.7207 \pm$ & 0.5982 & $-0.0150 \pm$ & 0.1906 & 11.7550 & 0. & .9006 & -0.0310 & 0.1348 & 8.2505 & \pm 1.8478 & 64 & -.- & $80 \%$ fibrous, $20 \%$ fat \\
\hline $59 \mathrm{a}$ & fibrous & 0.0218 & \pm 0.1849 & $12.1588 \pm$ & 0.9116 & $-0.0260 \pm$ & \pm 0.1774 & 11.9516 & \pm & .7793 & -0.0043 & 0.1653 & 7.8951 & \pm 0.6314 & 16 & $\ldots$ & $65 \%$ fibrous tissue, $30 \%$ fat, $5 \%$ epithelium \\
\hline $59 \mathrm{~b}$ & fibrous & 0.0591 & \pm 0.1932 & $10.3538 \pm$ & 1.5123 & $0.0366 \pm$ & \pm 0.1684 & 10.2179 & \pm & .2956 & 0.0227 & 0.1940 & 7.9944 & \pm 0.0095 & 16 & ..- & $65 \%$ fibrous tissue, $30 \%$ fat, $5 \%$ epithelium \\
\hline $60 \mathrm{a}$ & fibrous & -0.0195 & 0.1898 & $9.7566 \pm$ & 0.8090 & $-0.0271 \pm$ & \pm 0.1801 & 10.0048 & \pm & .3833 & $-0.0243=$ & \pm 0.1787 & 8.4943 & \pm 0.7019 & 24 & -- & $50 \%$ fibrous, $20 \%$ fat \\
\hline $60 \mathrm{~b}$ & fibrous & -0.0238 & 0.1906 & $13.0317 \pm$ & 2.0576 & $-0.0379 \pm$ & \pm 0.1815 & 10.3237 & \pm & 0593 & $-0.0406=$ & 0.1879 & 9.4029 & \pm 1.0035 & 24 & -- & $50 \%$ fibrous, $20 \%$ fat \\
\hline 62a & fibrous & 0.0343 & \pm 0.2016 & $9.6335 \pm$ & 1.7335 & $-0.0284 \pm$ & \pm 0.1804 & 10.3951 & \pm & 1.1742 & $-0.0245=$ & 0.1775 & 8.2817 & \pm 1.8964 & 64 & $\ldots$ & Mostly fibrous, $20 \%$ fat \\
\hline $62 \mathrm{~b}$ & fibrous & 0.0706 & \pm 0.1694 & 8.3035 & 0.5545 & $0.0559 \pm$ & \pm 0.1766 & 8.1649 & \pm & .0043 & 0.0226 & 0.1759 & 6.1467 & \pm 0.9455 & 64 & $\ldots$ & Mostly fibrous, 20\% fat \\
\hline 66 & fibrous & 0.0517 & \pm 0.1907 & 5.4748 & 0.4045 & 0.0287 & \pm 0.1855 & 5.4733 & & .0688 & 0.0306 & 0.1907 & 3.8866 & \pm 0.2275 & 16 & -.- & fibroadenoma \\
\hline 67 & fibrous & 0.1115 & \pm 0.1841 & $7.6569 \pm$ & 0.7736 & 0.0640 & \pm 0.1801 & 6.8821 & & .2744 & 0.0528 & 0.1910 & 4.5165 & \pm 0.5109 & 22 & .. & fibrous tissue and fat \\
\hline 74 & fibrous & 0.5098 & \pm 0.1865 & $10.1849 \pm$ & 0.1214 & 0.0921 & 0.1862 & 8.0615 & & .9356 & 0.0650 & 0.1873 & 8.3018 & \pm 0.4663 & 77 & 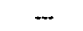 & fibrous and fat \\
\hline 80 & fibrous & 0.8639 & \pm 0.0239 & $7.9294 \pm$ & 2.2466 & 0.2205 & 0.1065 & 6.3801 & & .5962 & 0.1531 & 0.1342 & 7.1246 & \pm 1.0158 & 40 & - & fibrous tissue and fat \\
\hline 12 & fatty & 0.1181 & $\begin{array}{l} \pm \quad 0.2008 \\
\pm\end{array}$ & $10.4600 \pm$ & 2.5841 & 0.0704 & 0.1632 & 12.0780 & & 8071 & 0.2156 & 0.1653 & 9.7426 & \pm 1.0783 & 63 & $\ldots$ & $60 \%$ fat rest fibrous tissue \\
\hline 14 & fatty & 0.0414 & 0.1837 & $3.7537 \pm$ & 0.8048 & $0.0519 \pm$ & 0.1906 & 4.4437 & & .7236 & 0.1074 & 0.1812 & 5.2875 & 0.4425 & 67 & - & mostly fat with tiny cysts \\
\hline 17 & fatty & 0.3919 & 0.1698 & $12.4101 \pm$ & $\begin{array}{l}1.6392 \\
1.639\end{array}$ & 0.3153 & 0.1036 & 12.2570 & & .2205 & 0.2335 & 0.1500 & 12.1060 & 2.5209 & 56 & $\ldots$ & $60 \%$ fat with $40 \%$ fibrous tissue \\
\hline 18 & fatty & 0.1716 & $\begin{array}{ll} \pm & 0.1050 \\
\pm & 0.1905\end{array}$ & $15.5870 \pm$ & 0.5115 & 0.1112 & $\begin{array}{l} \pm .1754 \\
\pm \quad 0.1754\end{array}$ & 13.2120 & \pm & 8680 & 0.1887 & 0.1746 & 10.9300 & $\begin{array}{l} \pm \quad .0870 \\
\pm 1.080\end{array}$ & 58 & $\ldots$ & fat with strands of fibrous tissue \\
\hline 19 & fatty & 0.1776 & $\begin{array}{ll} \pm & 0.1500 \\
\pm & 0.1609\end{array}$ & $\begin{array}{l}10.0000 \pm \\
10.9620 \pm\end{array}$ & 1.1542 & 0.0822 & \pm 0.1666 & 9.9369 & \pm & 0303 & 0.1532 & 0.1828 & 12.0400 & \pm 0.5136 & 43 & .. & $\begin{array}{l}\text { fat with strands of fibrous tissue } \\
\text { fons }\end{array}$ \\
\hline 20 & 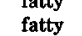 & 0.1374 & $\begin{array}{cc} \pm & 0.1609 \\
\pm & 0.1580\end{array}$ & $9.2487 \pm$ & 0.2956 & 0.0395 & $\begin{array}{l}-1721 \\
\pm \quad 0.1700 \\
\pm\end{array}$ & 8.1791 & $\begin{array}{l} \pm \\
\pm\end{array}$ & 4126 & 0.0690 & $\begin{array}{l}0.1573 \\
0.1573\end{array}$ & 9.4531 & $\begin{array}{l} \pm \\
\pm \\
\pm\end{array} 1.0116$ & 74 & $\ldots$ & fat with $20 \%$ fibrous tissue \\
\hline 21 & fatty & 0.2803 & $\begin{array}{l} \pm .1565 \\
\pm \\
\pm\end{array}$ & 7.9530 & 1.7892 & 0.1339 & \pm 0.1534 & 6.5053 & & .5746 & 0.1570 & 0.1712 & 6.8338 & 0.3336 & 27 & - & all fat \\
\hline $25 \mathrm{a}$ & fatty & 0.3050 & \pm 0.1293 & 7.2374 & 1.5952 & 0.3528 & \pm 0.0917 & 7.0227 & & .0852 & 0.1988 & 0.1088 & 6.4883 & 0.7752 & 30 & -- & predominantly fatty with streaks of fibrous tissue \\
\hline $25 \mathrm{~b}$ & fatty & 0.1805 & \pm 0.1135 & 8.6552 & 3.3608 & 0.0793 & \pm 0.1861 & 6.7230 & \pm & 3343 & 0.1161 & 0.1811 & 5.1472 & 1.1840 & 30 & -.- & predominantly fatty with streaks of fibrous tissue \\
\hline $25 \mathrm{c}$ & fatty & 0.3360 & \pm 0.1550 & 6.6181 & 0.3671 & 0.2601 & \pm 0.1181 & 6.0318 & \pm & .7819 & 0.3039 & 0.1597 & 7.5846 & 0.9904 & 30 & -. & predominantly fatty with s \\
\hline $25 \mathrm{~d}$ & fatty & 0.2238 & \pm 0.0978 & 7.3269 & 0.6749 & 0.1489 & \pm 0.1287 & 7.2633 & 0. & 2364 & 0.1947 & 0.1666 & 7.1060 & 1.7812 & 30 & & predominantly fatty $w$ \\
\hline $31 \mathrm{~b}$ & fat & 0.1194 & \pm 0.1878 & 5.2241 & 0.6049 & 0.0885 & \pm 0.1779 & 7.0244 & 2. & 1473 & 0.0723 & 0.1917 & 4.4489 & \pm 0.3386 & 68 & - & $80 \%$ fat, $20 \%$ fibmus \\
\hline $31 \mathrm{c}$ & fatty & 0,1343 & \pm 0.1625 & 7.3344 & 1.8692 & $0.1087 \pm$ & \pm 0.1748 & 7.1627 & 0. & 8763 & 0.1793 & & 6.0450 & $\pm \quad 1.0819$ & & --- & $80 \%$ fat, $20 \%$ fibrous tissu \\
\hline $38 a$ & fatty & 0.0572 & \pm 0.2015 & $12.7514 \pm$ & 2.9613 & $-0.0069 \pm$ & 0.1814 & 8.4934 & & 1477 & 0.0140 & 0.1811 & 7.0560 & 1.05 & & $\ldots$ & is \\
\hline $38 \mathrm{~b}$ & fatty & 0.3665 & \pm 0.1766 & $11.3410 \pm$ & 1.5572 & $-0.0424 \pm$ & \pm 0.1810 & 9.3001 & 1. & .2541 & -0.0204 & 0.1860 & 9.9423 & 1.38 & & -.- & fat, rest fibrous \\
\hline $49 a$ & fatty & 0.0004 & \pm 0.1921 & 4.5054 & 1.0622 & $-0.0412 \pm$ & 0.18 & 4.0278 & 0 . & 7086 & -0.0291 & 0.1772 & 3.6257 & 1.21 & 26 & _. & mostly fat, $20 \%$ fibrous \\
\hline $49 \mathrm{~b}$ & fatty & 0.0166 & \pm 0.2024 & 4.0621 & 0.2981 & -0.0366 & $\pm \quad 0.1758$ & 3.8916 & 0. & 6868 & -0.0230 & 0.1893 & 3.9649 & 0.0 & 26 & -.. & mostly fat. $20 \%$ fibrous tissue \\
\hline $54 \mathrm{~b}$ & fatty & 0.0241 & $\mp 0.2005$ & 4.4436 & 0.1507 & $0.0392 \pm$ & \pm 0.1853 & 4.9459 & 0. & .1601 & 0.2164 & 0.0272 & 4.6211 & 0.4871 & 46 & $\ldots$ & mostly fat, $20 \%$ fibrous tissue, $10 \%$ glands \\
\hline 68 & fatty & 0.0338 & \pm 0.1888 & 4.3421 & 0.3666 & 0.0197 & \pm 0.1823 & 4.5765 & 0. & 6785 & 0.0676 & 0.1770 & 6.2487 & 0.1986 & & - & fat with ar \\
\hline 69 & fatty & 0.0339 & \pm 0.1584 & $10.0184 \pm$ & 0.7278 & $-0.0485 \pm$ & \pm 0.1910 & 9.7421 & \pm & 1446 & -0.0465 & 0.1888 & 7.2343 & 1.5106 & $\ldots$ & ... & $\%$ fat $10 \%$ epit \\
\hline 71 & fatty & 0.0184 & \pm 0.1940 & 7.6501 & \pm 1.3615 & $0.0148 \pm$ & \pm 0.1883 & 8.0893 & \pm & 4313 & -0.0088 & 0.1839 & 6.2038 & 0.9768 & - & $\ldots$ & \\
\hline 73 & fatty & 0.5930 & \pm 0.1830 & 15.7746 & 1.5642 & $0.0685 \pm$ & \pm 0.1887 & 9.5180 & \pm 1. & 3508 & 0.0461 & 0.1653 & 6.4803 & 1.3011 & 71 & $\ldots$ & mostly \\
\hline 77 & fatty & 0.4663 & \pm 0.1735 & $7.3079 \pm$ & \pm 1.3426 & $0.0728 \pm$ & \pm 0.1650 & 6.0507 & & 2934 & 0.0704 & 0.1856 & 8.7090 & \pm 0.0709 & & - & mostly fat with areas of collagen \\
\hline & skin & 0.2428 & \pm 0.1920 & 0.7530 & 23.1405 & $0.7530 \pm$ & $\begin{array}{l} \pm 0.0632 \\
\end{array}$ & 22.7586 & \pm 1 & .2943 & 0.9767 & \pm 0.1522 & $15.9443 \pm$ & \pm 2.1584 & & & skin \\
\hline
\end{tabular}

*Negative values of absorption coefficient are small and obtained after the correlations have been made. $\mu_{\mathrm{a}}$ values are within the error of the measurement. 
(a)

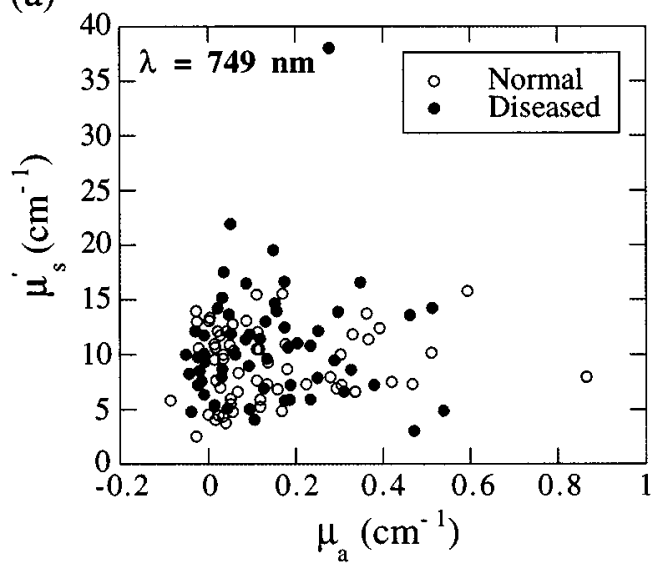

(b)

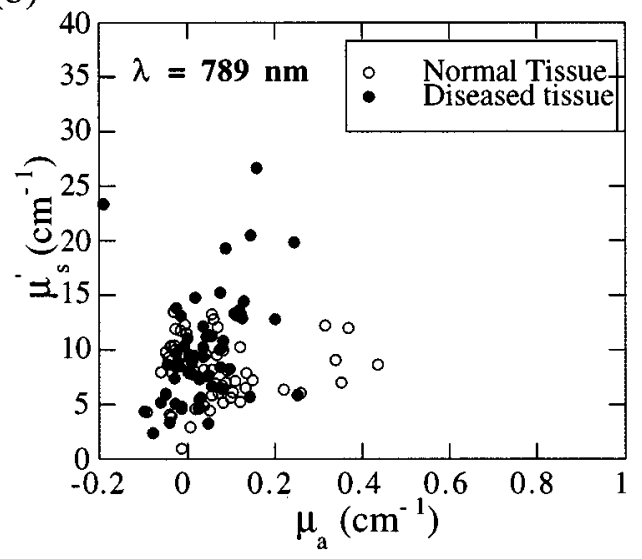

(c)

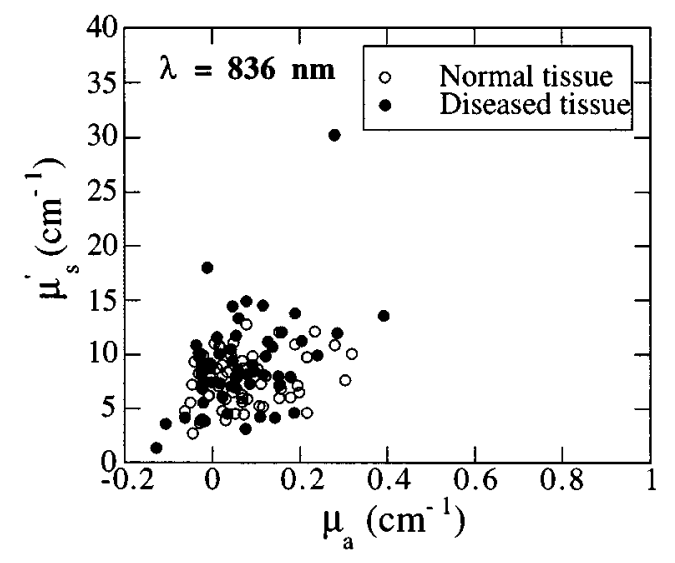

Fig. 5 Experimental optical properties of normal and diseased breast tissues reported as the isotropic scattering coefficient $\mu^{\prime}{ }_{s}$ versus the absorption coefficient $\mu_{a}$ measured at (a) 749, (b) 789, and (c) $836 \mathrm{~nm}$ where the open circles represent normal tissues and the closed circles represent diseased tissues.

between the scattering coefficients of ductal carcinoma in situ and normal fatty tissues. However, trends do exist. Infiltrating carcinoma and ductal carcinoma in situ have the highest scattering properties at each of the three wavelengths. This result is inconsistent with Peters et al., ${ }^{25}$ who report that cancerous tissues have lower scattering properties than fibrous tissue types.

In all tissue classifications, there are no observable trends of absorption coefficient with histopathology. Since tissue measurements are made in vitro, again it is unlikely that these measurements will accurately reflect the blood volume and hence the contrast due to absorption in vivo. However, Peters et al. $^{25}$ found that tissues with varying pathologies have differing absorbances, with carcinomas having the highest value of $\mu_{a}$.

\section{EXPERIMENTAL MEASUREMENTS PREDICTING $\mu_{A}$ AND $\mu_{S^{\prime}}$ OF NORMAL AND DISEASED BREAST TISSUES FROM THE SAME PATIENT}

From Figures 5(a) though 5(c) presented earlier, there is no consistent optical contrast provided between normal and diseased tissues pooled from 88 patients. In five tissue specimens, tissue volumes were significant, enabling optical property measurement of diseased and surrounding normal tissues. Table 4 lists the tissue optical properties for normal and diseased tissues for five patients with histological pathologies of (1) normal fibrous/ ductal carcinoma in situ, (2) normal fibrous/ infiltrating carcinoma, (3) normal fatty/infiltrating carcinoma, and (4) normal skin/mucinous carcinoma. In the last specimen, skin tissue was inadvertently sampled, as evidenced by histopathology. Interestingly, the scattering coefficient of skin is higher than normal fatty and fibrous tissues, which is in agreement with literature reports. ${ }^{28}$ The scattering coefficient of the mucinous tissue is low, which again is consistent with the pathology of the disease (see Sec. 2.4). While the number of measurements is small (due to the size of tissue samples), preventing statistical analysis, our results are nonetheless consistent in that the scattering coefficients of infiltrating carcinoma and ductal carcinoma in situ tissues are larger than the surrounding normal tissues, whether fatty or fibrous in nature. There appears to be no trend in the measured absorption coefficient, again probably due to the drainage of blood.

Recently, Gandjbakhche and co-workers ${ }^{29}$ found that a significant difference in measured in vitro scattering coefficients at 633 and $800 \mathrm{~nm}$ exists between fatty normal tissue and adenocarcinoma tissue specimens from one patient. Their results show a doubling of scattering coefficient between the fatty and adenocarcinoma tissue specimens, which is consistent with the increased scattering between normal and diseased tissues that we found in our study (with the exception of the patient with mucinous carcinoma). Their results show a reduction in absorption with disease, a trend that was not evident in our study. 
Table 3 Measured optical properties of classified breast tissue reported as the mean \pm the standard deviation of the mean at 749, 789, and $836 \mathrm{~nm}$.

\begin{tabular}{|c|c|c|c|c|c|c|}
\hline & \multicolumn{2}{|c|}{$\lambda=749 \mathrm{~nm}$} & \multicolumn{2}{|c|}{$\lambda=789 \mathrm{~nm}$} & \multicolumn{2}{|c|}{$\lambda=836 \mathrm{~nm}$} \\
\hline & $\mu_{a}\left(\mathrm{~cm}^{-1}\right)$ & $\mu_{s}^{\prime}\left(\mathrm{cm}^{-1}\right)$ & $\mu_{a}\left(\mathrm{~cm}^{-1}\right)$ & $\mu_{s}^{\prime}\left(\mathrm{cm}^{-1}\right)$ & $\mu_{a}\left(\mathrm{~cm}^{-1}\right)$ & $\mu_{s}^{\prime}\left(\mathrm{cm}^{-1}\right)$ \\
\hline $\begin{array}{l}\text { Infiltrating } \\
\text { carcinoma } \\
(n=48)\end{array}$ & $\begin{array}{c}0.1474 \\
\pm 0.1438\end{array}$ & $\begin{array}{r}10.9139 \\
\pm 5.5943\end{array}$ & $\begin{array}{c}0.0443 \\
\pm 0.0830\end{array}$ & $\begin{array}{r}10.1253 \\
\pm 5.0479\end{array}$ & $\begin{array}{c}0.1000 \\
\pm 0.1877\end{array}$ & $\begin{array}{c}9.0969 \\
\pm 4.5360\end{array}$ \\
\hline $\begin{array}{l}\text { Mucinous } \\
\text { carcinoma } \\
(n=3)\end{array}$ & $\begin{array}{c}0.2592 \\
\pm 0.1979\end{array}$ & $\begin{array}{c}6.1485 \\
\pm 2.4432\end{array}$ & $\begin{array}{c}0.0163 \\
\pm 0.0720\end{array}$ & $\begin{array}{c}5.0887 \\
\pm 2.4193\end{array}$ & $\begin{array}{c}0.0235 \\
\pm 0.1078\end{array}$ & $\begin{array}{c}4.7756 \\
\pm 3.6674\end{array}$ \\
\hline $\begin{array}{l}\text { Ductal } \\
\text { carcinoma } \\
\text { in situ } \\
(n=5)\end{array}$ & $\begin{array}{c}0.0763 \\
\pm 0.0682\end{array}$ & $\begin{array}{r}13.1065 \\
\pm 2.8521\end{array}$ & $\begin{array}{c}0.0234 \\
\pm 0.0339\end{array}$ & $\begin{array}{r}12.2055 \\
\pm 2.4505\end{array}$ & $\begin{array}{c}0.0386 \\
\pm 0.0678\end{array}$ & $\begin{array}{r}10.4586 \\
\pm 2.6502\end{array}$ \\
\hline $\begin{array}{l}\text { Fatty } \\
\text { normal } \\
(n=23)\end{array}$ & $\begin{array}{c}0.1838 \\
\pm 0.1590\end{array}$ & $\begin{array}{c}8.4768 \\
\pm 3.4283\end{array}$ & $\begin{array}{c}0.0818 \\
\pm 0.1045\end{array}$ & $\begin{array}{c}7.6728 \\
\pm 2.5670\end{array}$ & $\begin{array}{c}0.1077 \\
\pm 0.0973\end{array}$ & $\begin{array}{c}7.2739 \\
\pm 2.4003\end{array}$ \\
\hline $\begin{array}{l}\text { Fibrous } \\
\text { normal } \\
(n=35)\end{array}$ & $\begin{array}{c}0.1269 \\
\pm 0.1866\end{array}$ & $\begin{array}{c}9.7468 \\
+2.2704\end{array}$ & $\begin{array}{c}0.0604 \\
\pm 0.1193\end{array}$ & $\begin{array}{c}8.9450 \\
\pm 2.4502\end{array}$ & $\begin{array}{c}0.0499 \\
\pm 0.0832\end{array}$ & $\begin{aligned} & 8.0995 \\
+ & 2.20704\end{aligned}$ \\
\hline
\end{tabular}

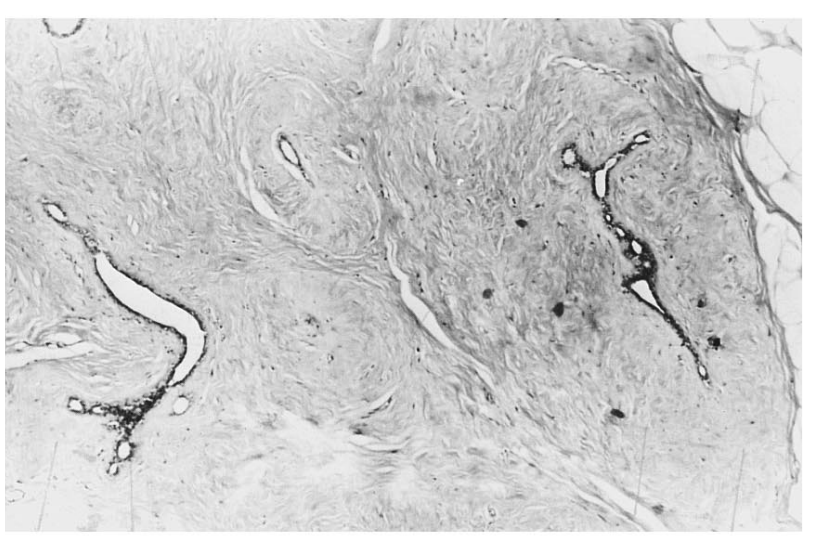

(a)

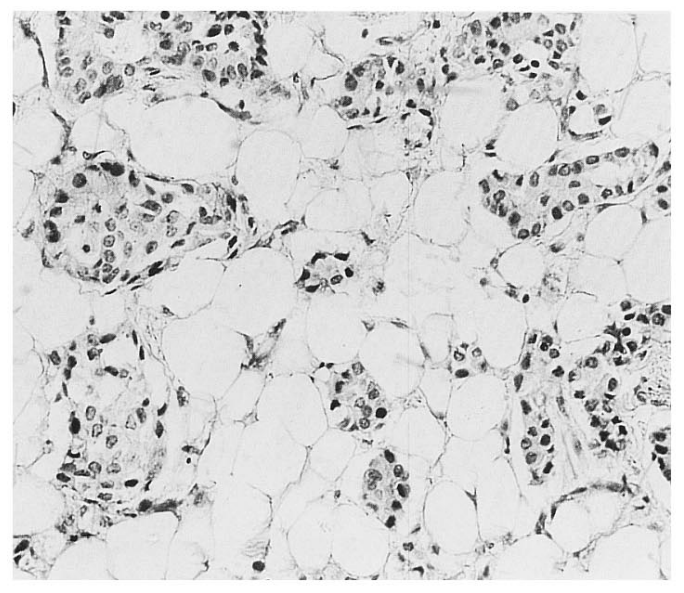

(c)

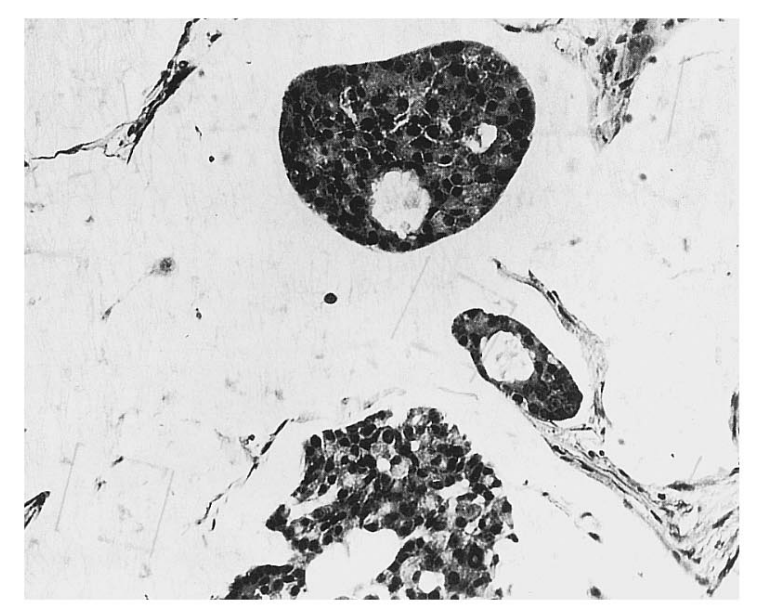

(b)

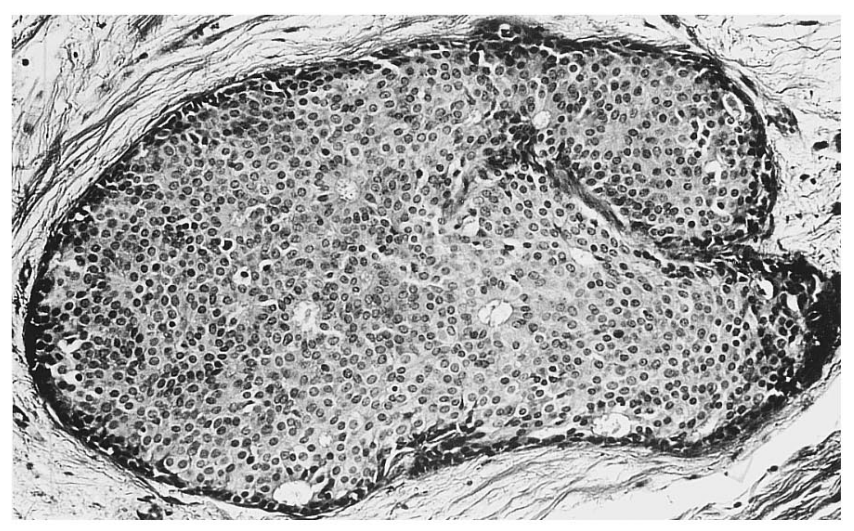

(d)

Fig. 6 (a) Micrograph of fibrous breast tissue with a fatty section in the upper right corner $(\times 80)$. Reproduced from Ref. 35. (b) Micrograph of breast tissue with mucinous carcinoma (×225). Reproduced from Ref. 35. (c) Micrograph of low-grade infiltrating carcinoma with tubule formation. The sharp clear spaces are fat $(\times 225)$. Reproduced from Reference 35. (d) Micrograph of ductal carcinoma in situ found in the breast $(\times 225)$. Reproduced from Ref. 35. 


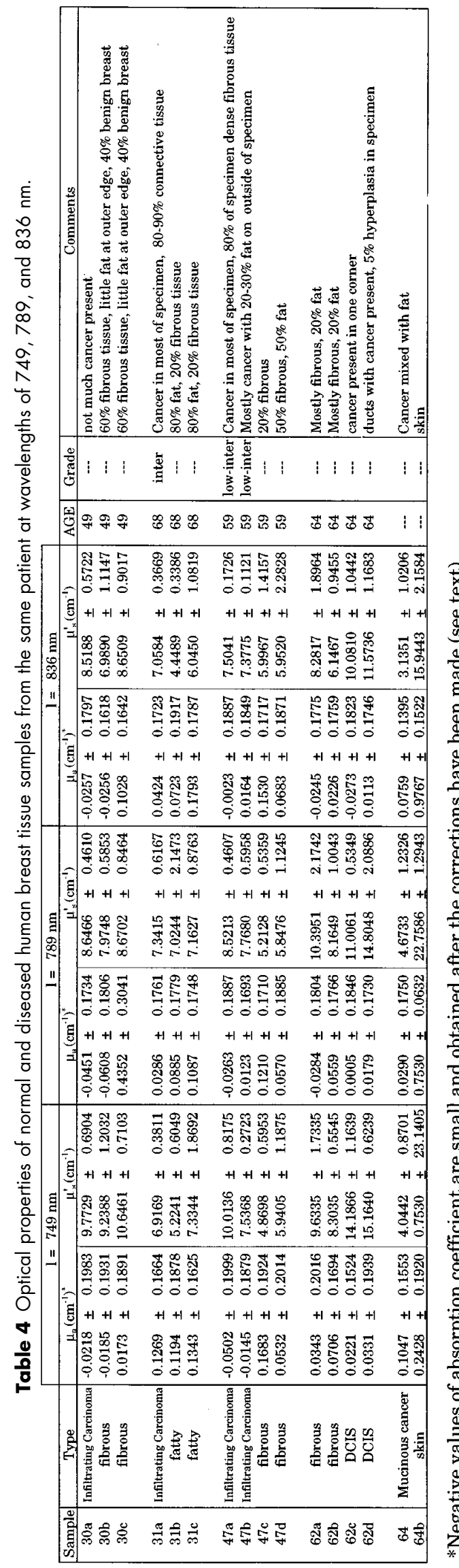

\section{CONTRAST FOR PHOTON MigRATION IMAGING}

The success of optical breast cancer screening depends crucially upon detecting the presence of diseased breast tissues from surface measurements of photon migration. Time-dependent measurements of photon migration can be made in one of two ways: in the time and frequency domains. In the time domain, an incident impulse of light is launched into the tissue. As the pulse propagates through the tissues, its migration and attenuation are influenced by local tissue optical properties. The broadened, reemitted pulse provides information about the scattering medium through which it has propagated. In the frequency domain, a photon density wave is launched into the tissue. As the wave of photons propagates, it is attenuated and phase shifted with respect to the incident wave due to the local tissue optical properties. These measurements provide input into inverse imaging algorithms for image reconstruction or can be used directly to reconstruct tomographic images. Yet the question remains: Are the optical property differences between normal and diseased tissues significant enough to distort these measurements of photon migration and provide detection of breast cancer?

In order to answer this question, we solved the forward-imaging problem to detect changes in photon migration measurements in which a simulated diseased tissue volume was located in an otherwise homogeneous medium. The optical properties of the $70-\mathrm{mm}$ diameter homogeneous medium were chosen to be identical to those measured at $749 \mathrm{~nm}$ for the fibrous normal tissues of patient 62 in Table 4. A 5-mm diameter diseased tissue volume with optical properties identical to those measured for the ductal carcinoma in situ in the same patient was embedded in the simulated tissue. While the high resolution for x-ray mammography is based largely upon the detection of calcifications, the minimal detectable volume for diseased tissues using optical tomography is not yet clear. Thus we arbitrarily choose to investigate optical tomography on a 5 $\mathrm{mm}$ tumor embedded in normal tissue. The diffusion equation that describes the local light propagation in tissues was solved in the time domain using commercial finite-element software (Fluid Dynamics International, Evanston, Illinois):

$$
\frac{1}{c} \frac{\partial}{\partial t} \Phi(r, t)-D \nabla^{2} \Phi(r, t)+\mu_{a} \Phi(r, t)=S(r, t) .
$$

In Eq. (2), $c$ is the speed of light in the medium $(\mathrm{cm} / \mathrm{s}), \Phi$ is the photon fluence rate (number of photons $/ \mathrm{cm}^{2} \mathrm{sec}$ ) at position $r$ and time $t, D$ is the optical diffusion coefficient $(\mathrm{cm})$, which is defined as 

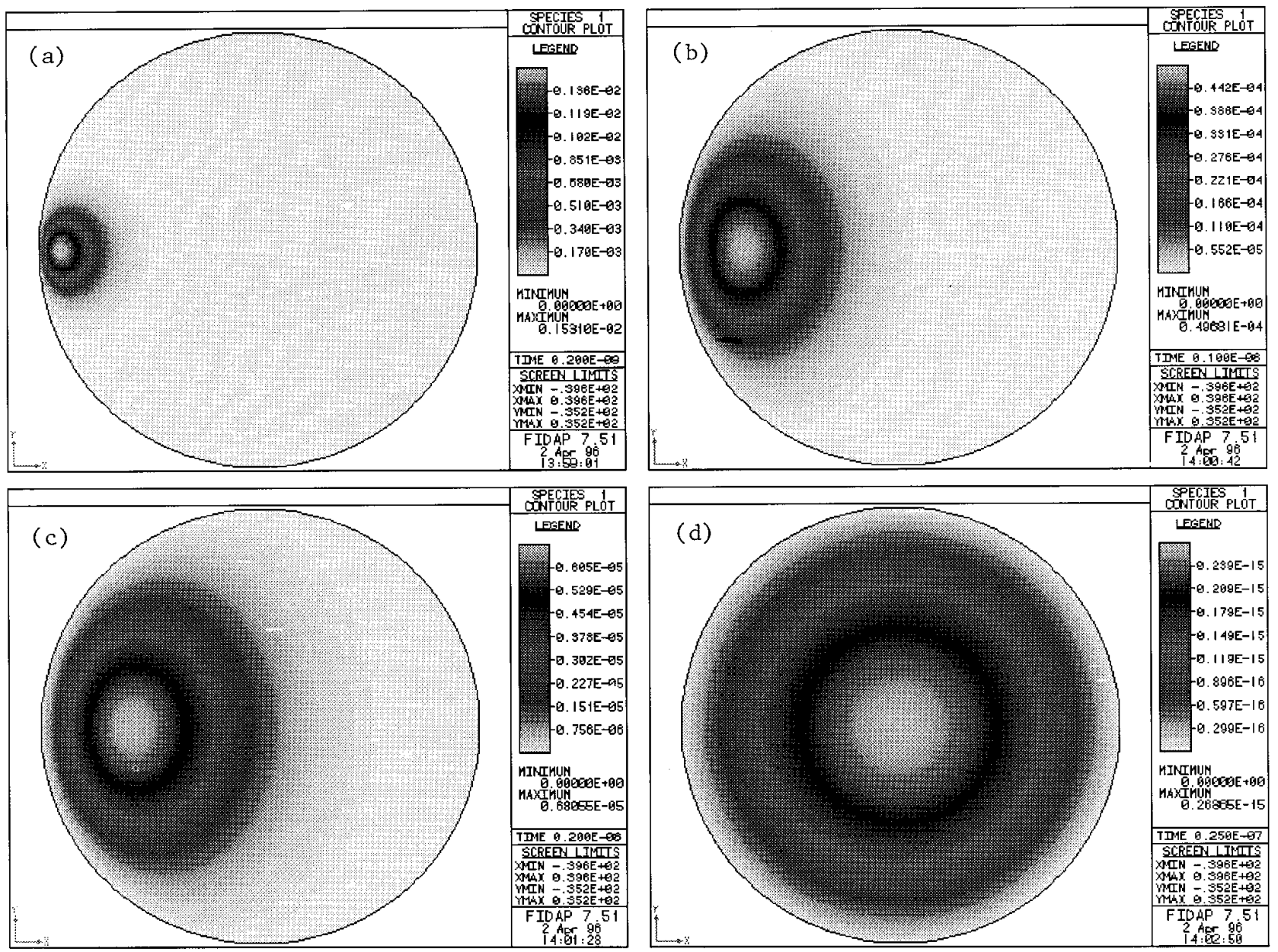

Fig. 7 Contour plots of the spatial distribution of light at (a) 0.2 , (b) 1, (c) 2, and (d) $25 \mathrm{~ns}$ in a heterogeneous phantom after an initial impulse. The heterogeneity $(0.5 \mathrm{~cm}$ in diameter) represents ductal carcinoma in situ tissue that is located $0.93 \mathrm{~cm}$ from the left edge.

$$
D=\frac{1}{\left(3 \mu_{a}+\mu_{s}^{\prime}\right)},
$$

and $S$ is the source term (number of photons $/ \mathrm{cm}^{3}$ sec). Since computations were prohibitive in three dimensions, we accounted for the twodimensionality of our simulation by noting that a scattering length in two dimensions has $(3 / 2)^{1 / 2}$ (Ref. 30) the length of a three-dimensional scattering length. These simulations therefore mimic detection of a $5 \mathrm{~mm}$ cylindrical diseased volume. Four different meshes consisting of approximately 1700 quadrilateral elements with 7000 nodes were constructed. At a node located one scattering length beneath the surface, an initial condition of finite fluence served to simulate the incident impulse of light. Zero fluence boundary conditions were imposed, allowing more rapid computation on a SunSparc 10 workstation. The error in our source location and zero boundary condition assumption is minimal compared with the results for partial current boundary conditions ${ }^{31}$ with an initial condition employing a surface node. ${ }^{32}$
Figures 7(a) to 7(d) are contour plots showing the simulated light propagation through the 2-D circular tissue phantom at times of $0.2,1,2$, and $25 \mathrm{~ns}$ after an initial impulse of light. The incident impulse is launched from a point source located at the left edge. As time progresses, the light pulse broadens and attenuates toward the center of the phantom due to symmetry. The presence of the tumor causes light to be "trapped" within the object because of multiple scattering events causing a higher intensity within the heterogeneity. From these results, one can see that the propagation of NIR light in tissue is influenced by the presence of diseased tissues with optical properties similar to what has been measured in this study. However, can this change in light propagation characteristics be measured noninvasively?

In order to answer this question, we used data from our time domain finite-element solution and converted it to frequency domain measurements of phase shift and amplitude modulation using the Fourier transform. ${ }^{33}$ For a detector located at an arc 


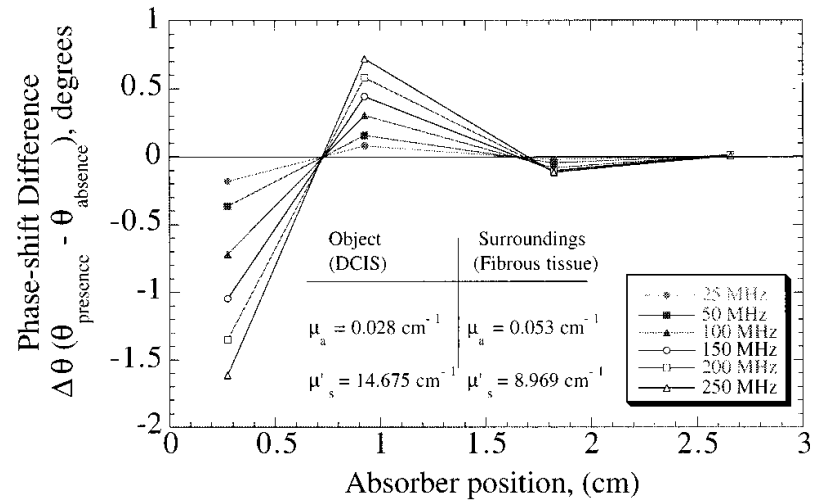

Fig. 8 Simulated phase-shift difference for a $0.5 \mathrm{~cm}$ diameter ductal carcinoma in situ heterogeneity in a $7 \mathrm{~cm}$ diameter normal tissue phantom as a function of object position away from the source and detector. Optical properties are taken from average values in Table 4 measured at $749 \mathrm{~nm}$.

distance of $3.05 \mathrm{~cm}$ away from the source, we simulated the change in phase shift caused by the diseased tissue volume as a function of the modulation frequency and the position of the heterogeneity away from the tissue-air interface. Figure 8 shows the simulated phase-shift difference at frequencies of 25, 50, 100,150, 200, and $250 \mathrm{MHz}$. This figure shows that the tumor causes an alteration in phase shift at depths of up to $1.8 \mathrm{~cm}$ at the measured frequencies. However, the maximum 2.3-degree change in phase shift may not be sufficient for detection. The presence of the heterogeneity can be determined at greater depths from lower frequencies and larger separations between the source and detector. ${ }^{8}$

\section{CONCLUSIONS}

Our results of optical property measurements of pooled tissue samples show that there are no statistical differences between normal and diseased tissues. However, these measurements underestimate absorption because of the blood drainage that occurs during excision. Therefore our measured absorption coefficients may not reflect the in vivo conditions. Since tumor angiogenesis may be responsible for increased vascularity and hemoglobin concentrations, ${ }^{34}$ we expect our in vitro measurements to underestimate the contrast caused by absorption. Nevertheless, our data show an increased scattering coefficient in infiltrating and ductal carcinoma in situ tissues relative to fatty and fibrous tissues. Indeed, when diseased and normal tissues from the same patient are compared, significant differences in optical properties can be seen.

\section{Acknowledgments}

The authors gratefully acknowledge the assistance of Julia Smith, Will Nau, Thomas Wadsworth, and Lesley Likens. Appreciation goes to Scott Prahl for his assistance with the double integrating spheres and the use of his inverse adding-doubling algorithm, and Britton Chance and Murray Penney for their critical advice, suggestions and comments. This work was supported in part by the Whitaker Foundation and the National Institutes of Health (R01CA 61413, EMS).

\section{REFERENCES}

1. E. Marshall, "Search for a killer: focus shifts from fat to hormones in a special report on breast cancer," Science 259, 618621 (1993).

2. R. J. Epstein, "Does the breast cancer dollar make sense?" Eur. J. Cancer 28, 486-491 (1992).

3. J. R. Singer, F. A. Grumbaum, P. Kohn, and J. P. Zubelli, "Image reconstruction of the interior of bodies that diffuse radiation," Science 248, 990-993 (1990).

4. B. B. Das, K. M. Yoo, and R. R. Alfano, "Ultrafast time-gated imaging in thick tissues: a step toward optical mammography," Opt. Lett. 18, 1092-1094 (1993).

5. J. C. Hebden, R. A. Kruger, and K. S. Wong, "Time resolved imaging through a highly scattering medium," Appl. Opt. 30, 788-794 (1991).

6. D. A. Boas, M. A. O'Leary, B. Chance, and A. G. Yodh, "Scattering of diffuse photon density waves by spherical inhomogeneities within turbid media: analytic solution and applications," Proc. Natl. Acad. Sci. U.S.A. 91, 4887-4891 (1994).

7. H. Jiang, K. D. Paulsen, U. L. Osterberg, B. W. Pogue, and M. S. Patterson, "Simultaneous reconstruction of absorption and scattering maps in turbid media from near-infrared frequency-domain data," Opt. Lett. 20, 2128-2130 (1995).

8. E. M. Sevick, J. K. Frisoli, C. L. Burch, and J. R. Lakowicz, "Localization of absorbers on scattering media using frequency domain measurements of time-dependent photon migration," Appl. Opt. 33, 3562-3570 (1994).

9. B. W. Pogue, M. S. Patterson, H. Jiang, and K. D. Paulsen, "Initial assessment of a simple system for frequency domain diffuse optical tomography," to appear in Physics in Medicine and Biology (1996).

10. R. L. Barbour, H. L. Graber, Y. Wang, J. H. Chang, and R. Aronson, "A perturbation approach for optical diffusion tomography using continuous-wave and time resolved data," Proc. SPIE IS11, 87-120 (1993).

11. M. S. Patterson, B. C. Wilson, and B. Chance, "Timeresolved reflectance and transmittance for non-invasive measurements of tissue optical properties," Appl. Opt. 28, 2331-2336 (1989).

12. B. Beauvoit, S. M. Evans, T. W. Jenkins, E. E. Miller, and B. Chance, "Correlation between the light scattering and the mitochondrial content of normal tissues and transplantable rodent tumors," Anal. Biochem. 226, 167-174 (1995).

13. B. Chance, H. Liu, T. Kitai, and Y. Zhang, "Effects of solutes on optical properties of biological materials: models, cells and tissues," Anal. Biochem. 227, 351-362 (1995).

14. M. A. O'Leary, D. A. Boas, B. Chance, and A. G. Yodh, "Experimental images of heterogeneous turbid media by frequency-domain diffusion-photon tomography," Opt. Lett. 20, 426-428 (1995).

15. H. Jiang, "Reconstructed near infrared diffusion imaging for breast cancer detection," Ph.D. diss., Dartmouth College, Hanover, NH (1995).

16. E. M. Sevick, J. R. Lakowicz, H. Szmacinski, K. Nowaczyk, and M. L. Johnson, "Frequency domain imaging of absorbers obscured by scattering," J. Photochem. Photobio, B:Biol 16, 169-185 (1992).

17. M. A. Franceschini, K. T. Moesta, S. Fantini, G. Gaida, E. Gratton, H. Jess, W. W. Mantulin, M. Seever, P. M. Schlag, and M. Kaschke, "Frequency-domain instrumentation enhances optical mammography: initial clinical results," Proc. Natl. Acad. Sci. U.S.A. (submitted April 1996).

18. J. W. Pickering, S. A. Prahl, N. van Wieringen, J. F. Beek, H. J. Sterenborg, and M. J. van Gemert, "Double-integratingsphere system for measuring the optical properties of tissue," Appl. Opt. 32, 399-410 (1993). 
19. S. A. Prahl, M. J. C. van Gemert, and A. J. Welch, "Determining the optical properties of turbid media by using the adding-doubling method," Appl. Opt. 32, 559-568 (1993).

20. B. C. Wilson and S. L. Jacques, "Optical reflectance and transmittance of tissues: principles and applications," IEEE J. Quant. Elect. 26, 2186-2199 (1990).

21. C. F. Bohren and D. R. Huffman, Absorption and Scattering of Light by Small Particles, Wiley, New York (1983).

22. Polyscience Inc. Particle Catalog, p. 25 (1995-96).

23. A. M. K. Nilsson, R. Berg, and S. Andersson-Engels, "Measurements of the optical properties of tissue in conjunction with photodynamic therapy," Appl. Op. 34, 4609-4619 (1995).

24. J. H. Torres, A. J. Welch, I. Cilesiz, and M. Motamedi, "Tissue optical property measurements: overestimation of absorption coefficient with spectrophotometric techniques," Lasers Surg. Med. 14, 249-257 (1993).

25. V. G. Peters, D. R. Wyman, M. S. Patterson, and G. L. Frank, "Optical properties of normal and diseased human breast tissues in the visible and near infrared," Phys. Med. Biol. 35, 1317-1334 (1990).

26. L. W. Dalton, D. L. Page, and W. D. Dupont, "Histologic grading of breast carcinoma: a reproducibility study," Cancer 73, 2765-2770 (1994).

27. W. J. Lennington, R. A. Jensen, L. W. Dalton, and D. L. Page, "Ductal carcinoma of the breast: heterogeneity of individual lesions," Cancer 73, 118-124 (1994).
28. M. J. C. van Gemert, S. L. Jacques, H. J. C. M. Sterenborg, and W. M. Star, "Skin optics," IEEE Trans. Biomed. Eng. 36, 1146-1154 (1989).

29. A. H. Gandjabkhche, R. Nossal, R. Dadmarz, D. Schwartzentruber, and R. F. Bonner, "Expected resolution and detectability of adenocarcinoma tumors within human breast in time-resolved images," Proc. SPIE 2387, 111-118 (1995).

30. C. L. Burch, "Monte Carlo simulations of photon migration in highly scattering media," Masters thesis, Vanderbilt University, Nashville, TN (1993).

31. M. Keijzer, W. M. Star, and P. R. M. Storchi, "Optical diffusion in layered media," Appl. Opt. 27, 1820-1824 (1988).

32. M. S. Patterson, S. J. Madsen, J. D. Moulton, and B. C. Wilson, "Diffusion equation representation of photon migration in tissue," IEEE MTT-S Int. Microwave Symp. Dig. 2, 905-908 (1991).

33. B. C. Wilson, E. M. Sevick, M. S. Patterson, and B. Chance, "Time dependent optical spectroscopy and imaging for biomedical applications," Proc. IEEE 80, 918-930 (1992).

34. J. Folkman, "Angiogenesis and breast cancer," J. Clin. Oncol. 12, 441-443 (1994).

35. D. L. Page and T. J. Anderson, Diagnostic Histopathology of the Breast, Churchill Livingstone, New York (1987).

Acknowledgment: The Publishers wish to acknowledge permission received from publishers and authors to reproduce figures used in this paper. 